\title{
АВТОМАТИЗАЦИЯ МОДЕЛИРОВАНИЯ СИСТЕМЫ ВНУТРЕННЕГО КОНТРОЛЯ НА ОСНОВЕ РИСК-ОРИЕНТИРОВАННОГО ПОДХОДА
}

\author{
() 2021 Сидорова М.И. \\ доктор экономических наук, доцент, заместитель декана по научной работе \\ Факультета международных экономических отношений, \\ руководитель научно-учебной лаборатории «ANAPLAN (Analitical Planning)» \\ Финансовый университет при Правительстве Российской Федерации, Россия, Москва \\ E-mail: MISidorova@fa.ru \\ (C) 2021 Кравцов М.С. \\ студент Факультета международных экономических отношений, \\ Научно-учебная лаборатория «ANAPLAN (Analitical Planning)» \\ Финансовый университет при Правительстве Российской Федерации, Россия, Москва \\ E-mail: crawtzov.misha@yandex.ru
}

В моделировании системы внутреннего контроля финансовой отчетности наиболее эффективно применение риск-ориентированного подхода. Соответственно, и автоматизацию также необходимо проводить на основе построения модели с учетом возможных рисков.

Ключевые слова: учет, анализ, аудит, автоматизация, моделирование, система внутреннего контроля, риск-ориентированный подход.

Для разработки оценки системы внутреннего контроля финансовой отчетности наиболее эффективно применение риск-ориентированного подхода. Определив существенные статьи и раскрытия в финансовой отчетности, а также значимые счета, команда проекта идентифицирует риски, относящиеся к каждому указанному элементу финансовой отчетности, и устанавливает источники этих рисков*.

Следующий пункт осуществления проекта состоит из оценки эффективности дизайна внутренних контролей и тестирования эффективности их выполнения.

Для начала стоит выделить, какими могут быть системы внутреннего контроля формирования финансовой отчетности:

- контроль инициирования, авторизации, регистрации, обработки операций, сверки остатков на счетах, а также составления раскрытий, включенных в финансовую отчетность.

- контроли, связанные с инициированием и обработкой нестандартных и несистематических транзакций (например, учетные записи, включающие суждения и оценки);
- контроль, связанный с выбором и применением соответствующих учетных политик;

- контроль, связанный с предотвращением, выявлением и обнаружением мошенничества;

- контроль за вводом итоговых записей в главную книгу;

- контроль за проведением периодических и неповторяющихся корректировок в финансовой отчетности.

Каждый контроль в первую очередь должен быть оценен в части эффективности его дизайна. Это означает, что контроль должен быть спроектирован так, чтобы способствовать снижению риска возникновения ошибки или мошенничества, которые могут привести к существенным искажениям в годовой или промежуточной финансовой отчетности, до допустимого уровня.

Чтобы руководство могло утверждать, что внутренний контроль за финансовой отчетностью эффективен, необходимы как оценка эффективности дизайна контроля, так и оценка его операционной эффективности. Последнее подразумевает под собой, что контроль выполняется и работает так, как задумано**.

\footnotetext{
* DeFond, M., Hung, M., Karaoglu, E., Zhang, J., 2007. Was the Sarbanes-Oxley Act good news for corporate bondholders? Working Paper, University of Southern California.

** Hollis Ashbaugh-Skaifea, Daniel W. Collinsb, William R. Kinney Jr, 2007. The discovery and reporting of internal control deficiencies prior to SOX-mandated audits. Journal of Accounting and Economics 44: 166-192.
} 
Существует три подхода к оценке операционной эффективности контроля:

- Самооценка. Сотрудники, выполняющие контроли или их непосредственные руководители самостоятельно оценивают средства контроля и сообщают результаты проектной команде по ВКФО. Эта форма проверки позволяет сотрудникам, обладающим необходимой квалификацией, подтверждать эффективность работы контролей в любое время, включая конец года и кварталов.

- Мониторинг. Мониторинг осуществляется на двух уровнях - уровне организации и уровне бизнес-процесса. В первом случае мониторинг и аналитика ведется на уровне всего экономического субъекта, во втором случае руководители бизнес-процессов осуществляют мониторинг за выполнением сотрудниками контрольных действий.

- Независимое тестирование контролей. Такое тестирование выполняется сотрудниками, ответственными за ВКФО.

Перед началом тестирования необходимо выполнить следующие действия:

1. Обозначить цели тестирования для каждого контроля. Например, если контроль направлен на авторизацию выплат, то его эффективность выражается в том, что выплаты были должным образом авторизованы и платежные документы подписаны уполномоченным сотрудником.

2. Определить тестируемую популяцию. «Популяция» состоит из всех транзакций, подпадающих под соответствующий контроль за какой-либо период. Важно четко сформулировать характеристики популяции, из которой должна быть сделана выборка из нескольких транзакций и на основе которых будет осуществляться тестирование контроля. Например, если контролер проверяет внутренний контроль за выставлением счетов за все поставки, соответствующая совокупность - это отправленные товары, а не оплаченные товары.

3. Указать период тестирования. Контроли могут тестироваться как на промежуточной основе, так и в конце финансового года. Это зависит от оценки рисков со стороны руководства, поскольку риски, связанные с операциями и записями в журнале в конце периода, весьма отличаются от рисков, связанных с обычными операциями, совершаемыми каждый день. Влияет и частота выполнения контроля (ежедневно, еженедельно, ежемесячно, ежеквартально или ежегодно).

4. Определить единицу выборки - образец, подлежащий проверке. Он представляет собой один элемент в популяции, например, документ, запись или позиция. Но следует помнить, что многие типы контролей не предполагают выбор образца из совокупности. Например, в некоторых случаях должна быть указана область, в которой могут соблюдаться меры контроля, например, в отношении разделения обязанностей и т.д.

5. Выбрать метод тестирования. Существует четыре основных метода тестирования: опрос, наблюдение, проверка и повторение контрольных действий.

Опрос наиболее полезен при подтверждении доказательств, полученных с помощью других методов тестирования. В опрос должны быть включены вопросы, направленные на выяснение, как осуществлялся контроль и с демонстрированием выполнения контроля на конкретном примере. Также сотрудник, проводящий опрос должен выяснить:

- умения и компетентность лиц, выполняющих контроль;

- всегда ли контроль предотвращал или обнаруживал ошибки или мошенничество;

- частота осуществления контроля.

Наблюдение является надежным методом тестирования средств контроля за физическим доступом в определенные ИТ-системы или помещения, объекты и за разделением обязанностей.

Инспектирование часто включает в себя установление того, существуют ли необходимые доказательства по выполнению контрольных действий относительно выбранной транзакции, например, наличие соответствующей авторизации, сопоставление данных поставщика и получателя по цене и количеству товара и т.д.

Повторение контрольных процедур - это наиболее трудоемкий метод тестирования контролей. Он подразумевает выбор транзакций и повторное ее выполнение, включая применение критериев авторизации, регистрации, обработки. Повторно выполненная или пересчитанная транзакция сравнивается с первоначально полученным результатом. Если между ними нет различий, то контроль признается эффективным.

Доказательства будут более надежными при сочетании всех указанных выше методов тести- 
рования ВКФО.

6. Определить размер выборки. На количество выбранных элементов из всей популяции влияет несколько факторов:

- если контроль имеет значительное влияние на достоверность информации, представленной в финансовой отчетности, необходимо расширить выборку для целей тестирования;

- контроль, являющийся ручным, требует также больший размер выборки.

Третий этап заключается в разработке предложений по улучшению ВКФО, включая соответствующие политики, методологии, отчеты и системы, задействованные в процессе выполнения внутренних контролей.

После того, как вышеуказанные предложения были разработаны, проектная группа должна проследить за осуществлением изменений в процессах реализации внутренних контролей.
В случае выявления недостатков и недоработок в контроле, проектная команда должна определить их причины и разработать решение по их устранению. Недостатки, касающиеся дизайна контроля, следует устранить за счет внесения изменений в описание контроля и инструкцию по его выполнению. Для операционных недостатков команда должна дать рекомендации по предоставлению необходимых полномочий или получению ответственным сотрудником необходимых компетенций.

Главная цель внутреннего контроля за финансовой отчетностью заключается в обеспечении ее надежности за счет своевременного выявления существенных недостатков или ошибок в процессе по формированию финансовой документации, способных привести к существенным искажениям в финансовой отчетности.

\section{Библиографический список}

1. Sarbanes-Oxley Act.: (официальный сайт) - URL: http://www.sarbanes-oxley-101.com/

2. The Committee of Sponsoring Organizations' (COSO): (официальный сайт) - URL: http://www.coso.org

3. Benchmarking SOX Costs, Hours and Controls: (официальный сайт) - URL: https://www.protiviti.com/US-en/ insights/sox-compliance-survey.

4. DeFondu M., Hung M., Karaoglu E., Zhang J., 2007. Was the Sarbanes-Oxley Act good news for corporate bondholders? Working Paper, University of Southern California.

5. Hollis Ashbaugh-Skaifea, Daniel W. Collinsb, William R. Kinney Jr, 2007. The discovery and reporting of internal control deficiencies prior to SOX-mandated audits. Journal of Accounting and Economics 44: 166-192. 